\title{
EDUCACIÓN Y REFORMA MUNICIPAL: PRÁCTICAS DELIBERATIVAS EN LOS CONCEJOS MUNICIPALES
}

\author{
Rudy Guerrero Portales ${ }^{1}$
}

\section{Resumen}

En este ensayo se analizan las necesidades de educación no formal para el fortalecimiento de las prácticas democráticas en los debates y deliberaciones de los concejos municipales en el marco de la reforma municipal que se inicia en abril de 2002, con la promulgación del nuevo Código Municipal en Costa Rica.

La institución municipal tan desprestigiada a lo largo de los años, no sólo tiene la oportunidad de revertir su imagen, sino que en buena medida, afrontar desafíos y proyecciones en un escenario local que reclama cambios y que las competencias que otorga la nueva legislación municipal pueden consolidar una verdadera plataforma de lucha regional. En este planteamiento se analizarán algunas necesidades educativas.

\section{Abstract}

It is analyzed in this essay, the necessities of non-formal education for the strengthen of the democratic practices in the debates and deliberations of the municipal councils inside a frame of municipal reform, that begins in apri1 2002, with the promulgation of the new Municipal Code in Costa Rica.

The Municipal Institution, so discredited along the years, not only have the opportunity to revert it's image, but in a good sense, to confront challenges and projections in a local scenario that claims for changes and the competitions that awards the new municipal Legislation, can consolidate a real platform of regional struggle. In this perspective, the education can help significantly.

\section{Palabras claves: reforma municipal, educación no formal y democracia de- liberativá.}

\footnotetext{
${ }^{1}$ Doctor en Estudios Latinoamericanos con mención en Pensamiento Latinoamericano. Profesor de la Maestría en Educación en el Centro de Investigación y Docencia en Educación (CIDE-UNA) Candidato a doctor en Educación en la Universidad de Costa Rica. Máster en comunicaciones para la paz (UPAZ). Licenciado en Estudios Latinoamericanos (IDELA/UNA) Licenciado en Periodismo. Universidad de Concepción, Chile.
} 


\section{A. Antecedentes}

$\mathrm{E}^{1}$

Estado costarricense busca el fortalecimiento del régimen municipal en el marco del proceso de descentralización. Para la consecución de este propósito se promulgó el nuevo Código Municipal (1998) que representa un hito en la institucionalidad del país por cuanto abre espacios para que diferentes actores sociales se involucren en acciones que favorezcan la apertura y consolidación de nuevos escenarios democráticos. En este orden la reforma municipal impulsa tanto la descentralización territorial como la autonomía de los gobiernos municipales con base en una mayor participación de ciudadanos en las decisiones que conciernen al gobierno local.

Ahora bien, si en el marco de la descentralización, se pone en práctica una reforma municipal a través de una nueva legislación, que abre foros de discusión pública como el cabildo, los ayuntamientos, el referéndum, el plebiscito, las audiencias públicas, los concejos de distrito y los concejos municipales, el escenario local adquiere particular trascendencia en cuanto a opciones y posibilidades para profundizar la educación para la democracia.

Los nuevos mecanismos de acción y participación popular permiten al ciudadano externar, en mayor medida, sus juicios y opiniones sobre del desarrollo de su comunidad. Sin embargo, no todo está claro, el desarrollo de la democracia local es un proceso en construcción que plantea necesidades educativas, que pueden expresarse, entre otras preguntas, corno la siguiente: ¿se puede fortalecer las prácticas deliberativas en la toma de decisiones en los concejos municipales, sobre todo, con base en la gestión del programa de gobierno del alcalde que señala el nuevo Código Municipal?

Un proyecto de respuesta a esta interrogante será, evaluar las necesidades educativas en los concejos municipales, con base en una propuesta de investigación educativa.

\section{B. La Municipalidad en Costa Rica}

El Dr. Roy Rivera es uno de los investigadores que ha trabajado los temas de organización municipal y descentralización en Costa Rica y en países de América Central, analiza en su libro Cultura política, gobierno local y descentralización, el desarrollo de las municipalidades en el país. En su investigación, señala, entre otras observaciones las siguientes: 
1. La municipalidad es la instancia de gobierno de menor escala territorial. Esta instancia es una reproducción en pequeña escala del Estado. Sin embargo, no cuenta ni con la misma base material para poner en práctica políticas de desarrollo local ni con las posibilidades reales de determinación política.

2. La municipalidad costarricense es un ejemplo de la hipertrofia institucional, que resulta de una organización político-administrativa hipercentralizada y un esquema municipal que ha restado posibilidades a las colectividades locales de propiciar prácticas de democracia local.

3. El régimen municipal contemporáneo se caracteriza por gobiernos locales que se han visto reducidos al triste papel de administradores de algunos recursos públicos deficitarios (2001:10ly 102).

Es obvio que ante un panorama tan desalentador, los ciudadanos pierden interés. Junto con la falta de recursos y la carencia de capacidad profesional y política, esta situación se traduce en apatía y desgano y forman un cuadro de serios obstáculos para el restablecimiento del régimen municipal.

En esta línea de antecedentes se analiza el papel de dos comisiones: la COREC y la CORIM.

Para la Comisión de Reforma de Estado-COREC-, el diagnóstico de la situación, evidencia un excesivo centralismo: ausencia de descentralización con favorecimiento del presidencialismo y ausencia de una ley orgánica de ministerios, de entes descentralizados y de empresas públicas. Según el planteamiento de la comisión, la descentralización debe darse en tres vertientes fundamentales: regional, no gubernamental y estatal.

- Regional

Esta modalidad enfoca la distribución de la competencia y autonomía del Poder central en las diferentes estructuras organizativas locales y provinciales.

- $\quad$ No Gubernamental

Se entiende como apertura a nuevas organizaciones sociales para realizar por autogestión, labores hasta ahora encargadas con el Estado. No debe confundirse con la privatización que es una cosa bastante distinta.

\section{- Estatal}

La descentralización estatal, o de los entes estatales; debe seguir varios pasos necesarios para llevarse a cabo, que incluyen la recuperación de autonomía de las instituciones autónomas, la eliminación del 
arrastre presidencial y fundamentalmente el fortalecimiento del régimen municipal.

Sin embargo el éxito de la descentralización según Calderón Suárez, debe basarse en un pilar fundamental cual es la planificación, (p. 4). En este proceso de planificación, se debe también tomar en cuenta la importancia de la educación para la democracia para reforzar y orientar las prácticas deliberativas en el ejercicio de las atribuciones en los consejos municipales. Con ello se espera coadyuvar en un cambio de mentalidad que garantice la operacionalidad y sostenibilidad de las reformas.

En este sentido, las palabras del constituyente Facio Brenes parecieran ilustrar acertadamente las ideas centrales de la descentralización.

La constitución de 1871 sirvió para que el personalismo natural del costarricense se desenvolviera y predominara sobre todo, o por lo menos no sirvió para ponerle coto. La Constitución de1 71 permitió la existencia de un Ejecutivo hipertrofiado y omnidecisivo, con mando sobre los empleados públicos, las finanzas, los Ministerios, el Congreso, el proceso electoral, la Corte, las Municipalidades, los designados a la Presidencia, etc. (1949:554).

Es interesante observar que en aquel momento la descentralización tenía dos grandes objetivos: a. eliminar de la influencia del ejecutivo una serie de labores que le permitían manejar al país a su antojo, b. otorgarles el ejercicio de esa función antes que las realizarán con criterios técnicos especializados.

En nuestros días es importante acompañar la descentralización como un proceso planificado que eleve el nivel de coordinación entre los entes y mejore las prácticas deliberativas en los concejos municipales. Esta coordinación podría darse por medio de un plan nacional de desarrollo, que sea a largo plazo con medidas específicas de ajuste al corto y mediano plazo y elaborado de adentro hacia fuera, lo que significa que sea preparado por nacionales y luego presentado como plan de acción a los organismos financieros internacionales y no al contrario, como ha venido sucediendo.

Una experiencia clara de descentralización sin planificación y coordinación, la constituye la reforma del sector salud en Costa Rica. De acuerdo con el artículo 38 de la Ley de salud, la base organizativa del sistema la forma el Sistema de Salud Local (SILOS), está conceptualizada sobre una base de participación ciudadana que trata de interrelacionar a los diversos actores 
de la localidad en un esfuerzo de acciones conjuntas con las instituciones centralizadas. Sin embargo, en palabras de Roy Rivera:

...la formulación es claramente centralista, verticalista y tecnicista, con lo cual se bloquean las posibilidades de un verdadero proceso de concertación. (1997:16).

Esta estrategia que se promueve en el campo de la salud le asigna roles activos tanto a la municipalidad como a la colectividad local. Sin embargo, en la mayoría de los casos no trasciende la orientación centralista, debido fundamentalmente a la posición de desventaja en la toma de decisión que tienen las municipalidades y las colectividades locales ante las instituciones del aparato central del Estado.

En cuanto a la coordinación entre los distintos actores en la escena local, que es la pretensión fundamental de la estrategia de los SILOS, se puede señalar que no existen los niveles esperados y que en lugar de la convergencia de esfuerzos de las distintas instituciones y de las representaciones de la localidad, lo que se da es únicamente la coordinación entre dos entes de matriz centralista: la Caja Costarricense de Seguro Social y el Ministerio de Salud. En este sentido la participación de otros actores, organismos privados y no gubernamentales ha sido muy limitada.

Como respuesta a la crisis que sufrió el Régimen Municipal desde las últimas décadas, en Agosto de 1993 se crea una Comisión Bipartidista encargada de estudiar, proponer e impulsar los acuerdos y las propuestas que desarrollaran las municipalidades del país, por medio de VII Congreso Nacional de Municipalidades.

Esta Comisión estaba integrada por representantes de los dos partidos mayoritarios y su principal tarea consistía en desarrollar una propuesta de reformas constitucionales, con énfasis en el artículo 170 de la Constitución Política, el cual trata expresamente sobre la autonomía municipal.

Después de las elecciones de 1994, esta Comisión Bipartidista instó a los partidos minoritarios a integrarse en su labor, denominándose, a partir de ese momento, con el nombre de Comisión Integral Municipal (CORIM).

En comienzo la agenda de discusión se centró en dos ámbitos: 


\begin{tabular}{|l|l|}
\hline \multicolumn{1}{|c|}{ 1. Reformas Electorales } & \multicolumn{1}{|c|}{ 2. Asuntos Financieros } \\
\hline - Elecciones Municipales separadas. & - Traslado de un porcentaje del Pre- \\
- Elección popular de ejecutivo. & supuesto Nacional. \\
\hline - Papel del síndico & Capacidad tributaria municipal \\
& - Artículo 169 de la Constitución Po- \\
& lítica Art. 169 de la Constitución \\
& Política \\
& - Partidas específicas. \\
& - Traslado de la administración del \\
& Impuesto Territorial. \\
& Impuesto de ventas. \\
\hline
\end{tabular}

La CORIM presentó al país nueve propuestas. La de mayor peso concierne a las Reformas Constitucionales. En esa propuesta se plasman las grandes reformas políticas que deben desarrollarse, desde el punto de vista de la CORIM, para fortalecer la autonomía en todos los campos del Régimen Municipal, como parte de la importancia que puede jugar la municipalidad en el proceso de descentralización política.

En primer lugar se interpreta que la autonomía municipal, señalada en el artículo 170 de la Constitución Política, debería darse en el campo político, funcional y financiero. En el caso de la autonomía política, se entiende que ésta nace por naturaleza electoral y representativa de su gobierno y, por ello, tiene potestad para fijar sus propios planes de acción sin interferencia externa, sea Gobierno central o instituciones autónomas. Este aspecto es de fundamental trascendencia por cuanto se conforma un nuevo espacio político en donde la democracia puede verse fortalecida.

De la autonomía funcional, se desprende la libertad para ejecutar los planes establecidos y generar, a la vez, los recursos económicos necesarios para que garanticen el cumplimiento de sus obligaciones, sean estas la prestación de servicios básicos u otros, de la población de su cantón.

En segundo lugar, según el artículo 169 de la Constitución, la CORIM interpretó a la corporación municipal como una comunidad local de base, integrada por un conjunto de vecinos o munícipes que habitan el cantón. Para ésta, los vecinos ejercen el gobierno con base en sus intereses y la administración de los servicios básicos por medio de la municipalidad, que es una entidad representativa en bien de su desarrollo. 
En tercer lugar, el Concejo Municipal, como órgano deliberativo, es un gobierno electivo y representativo de los habitantes del cantón. En él se discute y se analizan los problemas cantorales; es el espacio por excelencia en donde se delibera, y se analizan los problemas cantorales; es el espacio por excelencia en donde se delibera, se negocia y se vota. Sus integrantes se califican como concejales, en vez de regidores (reforma del artículo 171 de la Constitución Política) y a la vez proponen que la elección de estos representantes cantorales sea por cuatro años. Asimismo, delegan en la ley la composición de los concejos y la forma como estos actuarán.

En cuarto lugar, se propone desarrollar los comicios municipales en fecha diferente de la elección de presidente y diputado, aduciendo que esto permitiría una mayor independencia de los criterios político-electorales y la influencia partidista de la elección de los concejales, de ahí que se proponga una reforma al artículo 171 constitucional. Desde su punto de vista, esta medida fomentaría la participación masiva de los munícipes a las urnas, pensando más en su comunidad y en los programas que ofrecen los candidatos, que en los intereses del partido político al que pertenecen.

En quinto lugar, se propone una reforma al artículo 172, con el fin de transformar al ejecutivo municipal, electo por el concejo, en una alcalde de elección popular. La elección de este nuevo funcionario se realizarían el día en que se renueva el concejo y los vecinos votarían por una papeleta que contienen los nombres de un alcalde y de un alcalde suplente. El alcalde duraría en su cargo cuatro años y puede ser reelecto, con el objeto de no perder su experiencia administrativa y política.

Como sexto punto, se reformaría el artículo 173, con el propósito de transformar el régimen de representación de los distritos mediante síndicos, en una asamblea distrital, la cual designa un representante ante el Concejo con voz pero sin voto.

Como sétimo punto, la CORIM propuso una reforma al artículo 175 constitucional, para que la Asamblea Legislativa tenga la obligación de consultar a las municipalidades todos aquellos proyectos de ley relativos al Régimen Municipal en aras a fortalecer la autonomía municipal.

El octavo punto propone reformar los artículos 121 inciso 13 y el artículo 174 de la Constitución, para establecer normas de derecho financiero municipal y la autonomía financiera.

En este caso, la Asamblea Legislativa ya no establecería ni autorizaría los tributos de cada municipio ni sus exenciones, medida que si haría cada gobierno local. No obstante, para evitar abusos, antes de aprobar las tarifas impositivas se les prohíbe eximir de su pago a sujetos específicos. 
Además se pretendía en esta reforma, que cada gobierno local pudiera aprobar libremente sus presupuestos, previa consulta a los vecinos y sin requerir la autorización de ningún ente u órgano.

Otro aspecto propuesto por la CORIM fue autorizar a las municipalidades para contratar empréstitos, dar en garantía sus rentas o bienes y enajenar estos sin autorización legislativa, previa consulta a los vecinos y la fiscalización de la Contraloría.

Por último, se propuso una reforma al artículo 170, con el fin de que se asignara una suma no menor al cinco por ciento del Presupuesto Ordinario de la República, para todas las municipalidades del país. La propuesta buscaba evitar que un solo partido controle la distribución de los recursos, estos los percibirá el régimen, independientemente de los ingresos que percibe por sí mismo.

\section{Municipalidades y gobiernos locales}

Es importante explicar algunos elementos jurídicos que definen los parámetros señalados por la Constitución Política. Por ejemplo, el artículo 170 de la Carta Magna, establece: “...Las corporaciones municipales son autónomas..." En seguida el artículo 188 expresa: “...Las instituciones autónomas del Estado gozan de independencia administrativa y están sujetos a la ley en materia de gobierno. Sus directores responden por su gestión".

Tanto los gobiernos municipales como las instituciones autónomas son entes descentralizados del Estado y como tales están sujetos a una administración descentralizada. De acuerdo con el artículo 170, se debe interpretar que éste le confiere a las municipalidades la potestad de dictar sus propias normas, además de un grado de independencia especial o total respecto a cualquier otro ente, en ausencia de un superior jerárquico.

También es importante recordar que en el artículo 188, la autonomía se ve afectada junto con su margen de maniobra, puesto que según este artículo se brinda la oportunidad de que, por vía indirecta, otros entes, como por ejemplo la Asamblea Legislativa, establezcan y aprueben los impuestos municipales y, por lo tanto, influyan en los ingresos de los gobiernos locales.

Con base en lo expuesto, no se debe perder la perspectiva en relación con la autonomía de los municipios. Implica, naturalmente, la existencia de una serie de derechos por encima de los delEstado. Sin embargo, es pertinente recordar que el municipio es una parte integrante del Estado costarricense, por lo que es difícil separarlo del todo, básicamente si ambos tienen como finalidad la búsqueda del bienestar social, cada uno dentro de su ámbito de 
acción; el Estado en el espectro nacional y la municipalidad en el espectro cantonal correspondiente. Aquí se ve lo que podría aportar un diálogo pedagógico para reforzar las prácticas deliberativas de coordinación.

Para el politólogo Jorge Vargas Cullel, subdirector del proyecto Estado de la Nación, un importante desafío para los municipios será la capacidad de negociación entre el alcalde y los munícipes, de tal forma que no arriesgue la gestión ni la estabilidad del gobierno municipal. (La Nación, 27 de octubre de 2002. P. 5A). Según el Dr. Vargas Cullel, también está por verse si el nuevo instrumento democrático incrementa la rendición de cuentas de los ayuntamientos y los convierte en entidades más responsables y eficaces.

Los alcaldes asumieron sus funciones el primer lunes de febrero del 2003, comenzó a regir un conjunto de reformas del Código Municipal aprobadas en 1998. Uno de los más importantes es que el concejo pierde la potestad de definir las políticas y prioridades de desarrollo pues los lineamientos los define el plan de gobierno del alcalde electo.

En la práctica, el concejo se convierte en un órgano deliberativo y el presidente municipal en un director de debates. Según Giselle Mora, directora ejecutiva de la Universidad Nacional de Gobiernos Locales: "El alcalde llegará con una actitud diferente: muy abierto y comprometido con la comunidad. El concejo tendrá que asumir que su posición es de legislar y no meterse en las cosas del alcalde, que será el responsable de gestionar" (La Nación 27 de octubre de 2002. P. 5A).

En resumen, el nuevo Código Municipal, dice que el primer domingo de diciembre posterior a la elección presidencial, se deben elegir:

- Un alcalde municipal y dos suplentes: Hubo 368 candidatos que se disputaron las 81 alcaldías del país y 736 que se postulan como suplentes. $\mathrm{El}$ alcalde es quien dirige el funcionamiento de la municipalidad, autoriza los egresos del ayuntamiento y vigila, entre responsabilidades, el cumplimiento de acuerdos tomados por el concejo. Tiene poder de veto sobre esas responsabilidades.

- Síndicos y síndicos suplentes: Hubo 3.485 aspirantes por una plaza en 457 distritos. El síndico representa a su respectivo distrito ante la municipalidad. Tiene voz en las discusiones, pero no voto. Coordina el concejo de distrito.

- Miembros de concejo de distrito: Hubo 11.440 personas tras las cuatro sillas titulares y cuatro suplencias, en total, 3.656 plazas. El concejo de distrito es el órgano que se encarga de fiscalizar la actividad municipal en su respectiva comunidad. 


\section{Gobierno local y descentralización}

La propuesta descentralizadora se inscribe en el contexto de la reforma del Estado y en la dinámica de cambios del mercado expresados, entre otras cosas, en la liberalización y la privatización. La descentralización se presenta como un proceso necesario de transferencia de responsabilidades del gobierno central a otros niveles de gobierno e instituciones públicas subordinadas. Este proceso abarca la desconcentración administrativa, la descentralización fiscal y el traspaso de recursos y autoridad política a los gobiernos locales.

En el ámbito local del gobierno, la descentralización se presenta como una condición necesaria para la participación ciudadana, ya que ésta puede impulsar la cooperación, la integración social y la modernización de la administración pública. La participación ciudadana, tanto institucional como la que llevan a cabo las organizaciones y grupos autónomos, se considera un aspecto central para la gestión local y, para el fortalecimiento de la democracia en los concejos municipales.

El proceso de descentralización está en concordancia con los planteamientos de la Comisión Consultiva para la Reforma del Estado y, en este sentido, la Administración Calderón Founier planteó la descentralización de servicios públicos a las municipalidades como un componente del Programa de Reforma del Estado. Se hizo un diseño de reformas en lo económico, que permitieran acompañar la transferencia de servicios con un incremento de los ingresos de las municipalidades por medio de cambios de instrumentos y mecanismos de financiamiento local. En lo político, planteó la incorporación de reformas estratégicas como elecciones municipales independientes de las elecciones del Presidente y los Diputados; elección de un Alcalde como la cabeza el Municipio, en sustitución del Ejecutivo Municipal; elección de los Regidores en forma individual en sustitución del método actual de papelera colectiva.

No obstante, esta visión novedosa de la descentralización, surgen obstáculos que el proceso podría enfrentar, como las siguientes y en donde un programa de educación no formal podría coadyuvar significativamente en su mejoramiento. Ellos son, según Justo Aguilar y Violeta Pallavicini (Los Desafíos de la Descentralización, 2002:29), dos importantes:

a. Escepticismo y falta de entusiasmo de la sociedad costarricense en la política local. Esto podía explicarse en parte por la larga tradición centralista del país, lo cual ha creado falta de confianza y apoyo al gobierno 
municipal, tanto en la opinión pública como entre los líderes comunales. Esta desconfianza presenta algunos indicadores de interés si se toma en cuenta que entre 1998 y 2000 un total de 48 alcaldes dejaron sus puestos. De estos 22 alcaldes renunciaron y 21 fueron destituidos por sus Concejos (Estado de la Nación, 2001:343). Otra circunstancia preocupante es la disminución de los índices de votación en las elecciones nacionales.

b. Limitada capacidad de los gobiernos locales para responder a demandas de su comunidad: Un verdadero reto deberán enfrentar las nuevas autoridades que será adecuar las capacidades institucionales de los gobiernos locales a la satisfacción de las necesidades locales. Deberán desarrollar una sólida capacidad de negociación para poder aprovechar los diversos arreglos institucionales que les permitieran cumplir con su programa de gobierno.

\section{E. El nuevo Código Municipal}

El nuevo Código Municipal fue aprobado el 30 de abril de 1998, en las postrimerías de la administración Figueres Olsen y representa el hito más importante para el régimen municipal del país.

El nuevo Código incorporó cinco elementos sustantivos que permitirían mejorar la organización y funcionamiento de las municipalidades: a. la elección directa de Alcalde, lo que reforzará la autonomía política de la municipalidad; b. eliminación de los tutelajes que ejercía la ARESEP sobre la autonomía municipal al permitirle incrementar sus tarifas por decisión del Concejo Municipal; c. la creación de los Concejos Municipales de Distrito como sustrato del gobierno local que ejerce cada municipalidad en los diferentes cantones del país; d. un replanteamiento de la autoridad del Concejo Municipal para autorizar los precios, patentes, contribuciones y retribuciones privadas que corresponden a los servicios municipales; y finalmente, la capacidad del Concejo Municipal para crear empresas e servicios municipales.

Sobre organización municipal que establece el nuevo Código Municipal se propone una nueva concepción de gobierno municipal, basado en una diferenciación entre el Concejo Municipal con la responsabilidad de fijar la política institucional y de ejercer funciones contraloras sobre la gestión institucional frente al Alcalde (electo directamente por los ciudadanos del municipio en fecha diferente a los concejales) quien asume la responsabilidad de formular el plan institucional y de ejecutarlo como fundamento de la administración 
municipal. Bajo este enfoque el gobierno municipal está conformado por el Concejo Municipal (integrado por los regidores), el Alcalde municipal (con voz pero sin voto en el Concejo Municipal) y los Concejos de Distritos (integrado por miembros propietarios y suplentes, siendo dos de ellos los Síndicos titular y suplente) todos ellos de nombramiento popular.

Con respecto a la elección de los regidores, se mantiene el sistema vigente y en forma conjunta con las elecciones nacionales de Presidente de la República y sus Diputados. Sin embargo, la elección de Alcalde Municipal y sus dos suplentes, así como de los miembros de los Concejos Distritales son electos el primer domingo de diciembre del mismo año en que se realizan las elecciones de regidores. En la nueva legislación municipal se especifican las atribuciones del Concejo Municipal, del Alcalde y del Concejo Distrital, introduciéndose como una novedad el hecho de que el Alcalde debe presentar (antes de entrar en posesión de su cargo) un programa de gobierno para su gestión, sobre el cual el Concejo fija la política y las prioridades de desarrollo. Esto significa que el Alcalde asume la conducción administrativa y la organización municipal, mientras que el Concejo se le reserva el gobierno y la fiscalización sobre la buena marcha de la administración municipal. El nuevo Código mantiene el poder del Concejo Municipal para nombrar a los miembros de las Juntas Administrativas y las Juntas de Educación de los Centros Educativos localizado en sus jurisdicción cantonal.

\section{F. Participación ciudadana y elecciones municipales}

Uno de los términos que se maneja reiteradamente en el proceso de reforma municipal es participación ciudadana. Es un concepto que está directamente relacionado con el significado de representatividad como mecanismo de democracia directa, donde se supone que. donde hay más participación de la sociedad hay más democracia y, por ende. mejor gobierno.

Es así como el fin último de la "democratización" de los procesos electorales es precisamente el desarrollo de mecanismos que permiten a los gobernados incidir no sólo en la toma de decisiones sino en la práctica de las mismas, - ¡tarea nada fácil! - si se toma en cuenta el fenómeno de apatía que se experimenta en muchos países de la región respecto al sistema político electoral. En Costa Rica pareciera que la elección de Alcaldes no despertó especial entusiasmo e interés. Confirma esta apreciación la última encuesta de la empresa Lnimer-Research Internacional que reveló el elevado desconocimiento de los costarricenses acerca de la elección de alcaldes y la posibilidad de 
que hay un alto abstencionismo: el $74 \%$ de los ciudadanos no conoce a los aspirantes a la alcaldía y apenas 32 de cada 100 personas están decididos a votar (La Nación, 27 de octubre de 2002). Este panorama de apatía se ratifica en otro dato que informa la encuesta mencionada; el $77 \%$ de los ciudadanos tienen poca o ninguna confianza con los gobiernos municipales y solo el $13 \%$ serían de esas instituciones.

Ahora bien, ¿la elección popular del alcalde mejora la eficiencia de las municipalidades y hará más trasparentes las prácticas democráticas de sus respectivas instancias deliberativas? ¿las acercará a sus comunidades y estimulará la participación de los vecinos? Calos Sojo, Director de la Facultad Latinoamericana de Ciencias Sociales en un artículo publicado en el periódico La Nación, destaca el papel de una política democrática y transparente. Agrega: “...los municipios se han ocupado de unos pocos servicios, pero en el futuro deberán involucrarse activamente en la promoción el desarrollo en su comprensión integral. Estando "en contacto" con la comunidad podrán vislumbrar la solidaridad y fortalecer la confianza interpersonal, aspectos todos que son contenidos esenciales para la formación del capital social" (25 de setiembre de 2002. P. 17A).

Recapitulando lo expuesto, se han desarrollado los antecedentes del régimen municipal, las municipalidades y los gobiernos locales, los alcances más relevantes del nuevo Código Municipal, la participación ciudadana y las elecciones municipales. Todo ello conforma una nueva estructura municipal que abre espacios democráticos como los concejos municipales en donde las prácticas deliberativas tanto en el ejercicio de las atribuciones que señala la legislación como las negociaciones del programa de gobierno del alcalde con los munícipes que forman el concejo, plantea posibilidades de profundización democrática que pueden fortalecerse con la aplicación de un programa de educación no formal, cimentado sobre lineamientos didácticos de prácticas deliberativas.

\section{G. Democracia y prácticas deliberativas}

E1 término demokratia fue acuñado en el siglo $\mathrm{V}$ a. de $\mathrm{C}$. y desde entonces hasta hace aproximadamente un siglo ha sido un concepto político. Es decir, la democracia significaba democracia política. Actualmente, se habla también de democracia en un sentido no político, como cuando oímos hablar de democracia social, democracia industrial, democracia económica y democracia deliberativa. 
Sin embargo, el vocablo "democracia" sin calificativo representa, según Sartori, la "democracia política" (32), por lo tanto, la democracia es primero y principalmente un concepto político. En cambio, Touraine afirma que la democracia es el régimen en que la mayoría reconoce los derechos de las minorías, porque acepta que la mayoría de hoy puede volverse minoría mañana y verse sometida a una ley que representará intereses diferentes de los suyos sin por ello negarle el ejercicio de sus derechos fundamentales (32). Ambos autores, Sartori y Touraine, coinciden en que la democracia es el reconocimiento del derecho de los indi-

La descentralización se presenta como una condición necesaria para la participación ciudadana, ya que ésta puede impulsar la cooperación, la integración social y la modernización de la administración pública. La participación ciudadana, tanto institucional como la que llevan a cabo las organizaciones y grupos autónomos, se considera un aspecto central para la gestión local y. para el fortalecimiento de la democracia en los concejos municipales viduos y de las colectividades a ser actores de su historia y no verse liberados únicamente de sus opresores.

Este orden de consideraciones incide en el análisis de la teoría democrática. Y sobre este aspecto, es pertinente mencionar a Gina Zablidovsky, investigadora mexicana, quien sostiene que la teoría democrática ya no puede descansar en una concepción de la política territorialmente delimitada, textualmente expresa: "Sin llegar a desplazar el Estado-nación como punto de referencia, es necesario reflexionar sobre su papel en relación con un "sistema político" donde su "autoridad exclusiva" se ve limitada por organizaciones y actores "externos". El nuevo orden internacional, se caracteriza tanto por la persistencia de Estados soberanos como por el surgimiento de una pluralidad de estructuras de autoridad" (1995:105).

Parece evidente que en la sociedad actual, la democracia tiene que ser concebida a la luz de nuevas relaciones nacionales e internacionales que, normalmente. se manifiestan en transformaciones económicas, sociales, culturales y políticas como los cambios derivados de la globalización, descentralización y reforma municipal.

House y Howe (1990), quienes en el proceso de evaluación democrática, consideran tres dimensiones que son: deliberación, inclusión y diálogo. 
La primera dimensión corresponde al razonamiento reflexivo con respecto a los aspectos relevantes que incluyen la identificación de preferencias y valores de las y de los involucrados con relación a lo evaluado. La inclusión constituye la aclaración y consideración de los intereses relevantes de las diversas personas interesadas a quienes afecta, de una u otra manera, lo evaluado. $\mathrm{La}$ dialogicidad consiste en el establecimiento de espacios para que, tanto los involucrados como las y los evaluadores, puedan intercambiar sus opiniones, discutir sus intereses, y presentar con respecto a lo que se evalúa.

Las opciones propuestas dentro de este enfoque comprensivo de la realidad pretenden ampliar la participación de diversas personas relacionadas con lo que se evalúa, pero a la vez se le asigna un rol protagónico a la persona que evalúa, quien asume su papel facilitador que tiene como fin aclarar las reconstrucciones emergentes que surjan en el proceso, por parte de los diferentes grupos involucrados. La persona que evalúa es participante clave pues se encarga de reconstruir las realidades de las diferentes personas con respecto a lo evaluado.

Es importante observar que el rol asignado a la persona que evalúa incorpora un elemento adicional para la comprensión de este enfoque evaluativo, ya que la dicotomía sujeto-objeto, en realidad no es superada sino que persiste en la relación de la persona que evalúa con respecto a los demás involucrados (sean éstos evaluados o participantes en general), en tanto el evaluador es quien incorpora nueva información, interpreta los aportes de las diferentes personas, devuelve información a los demás y establece así mecanismos de influencia. El consenso se logra con base en la dinámica y acción de la persona que evalúa, quien se convierte en la figura clave del proceso. Por lo tanto, el evaluador mantiene el poder y puede así fortalecer la tendencia de quien contrate la evaluación. Surge aquí elementos éticos y políticos relacionados con la coerción, la manipulación y el conflicto de intereses entre las personas participantes.

Este modelo que aporta categorías de análisis como la deliberación, la inclusión y el diálogo es cuestionable en cuanto a la puesta en discusión de la construcción que cada cual hace acerca de lo evaluado, sin que medie una actitud crítica ni reflexiva, puede dar como resultado la aceptación de ideas (representaciones, significados y otros) sobre la realidad que reproduzcan la ideología imperante y que fortalezcan la falsa conciencia. De este modo las relaciones de inequidad y desigualdad tienden a perpetuarse mediante el sutil mecanismo ideológico de integrar, mediante el consenso, las construcciones acríticas de los involucrados. 
Para concluir el análisis de este modelo de evaluación, pareciera que se centra en la dinámica interna de las instituciones, olvidando el estudio de las fuerzas sociopolíticas, económicas y culturales que confluyen e intervienen en lo evaluado y en la evaluación. Sin embargo, considero que es posible replantear las tres dimensiones: deliberación, inclusión y diálogo, -como referentes teóricos- para adaptarlas en el diseño de un modelo de observación en los concejos municipales.

Otro autor que ha realizado estudios sobre democracia deliberativa es el noruego Jon Elster quien es profesor de Ciencias Políticas en la Universidad de Chicago y Director del Instituto de Investigaciones Sociales de Oslo. En su libro "La democracia deliberativa" aborda el controversial tema del escepticismo acerca de la democracia y su capacidad de representar a los ciudadanos sólo por el hecho de votar. Explica el autor que muchas veces se da por sentado que las elecciones son el mecanismo central de la toma de decisiones en política. Sin embargo, hay otras formas adicionales o alternativas de practicar la democracia: la decisión por medio de la discusión o por la vía de la deliberación.

Elster es el compilador de diez investigaciones reunidas en el libro y comprende estudios de casos históricos y actuales sobre la práctica de la democracia deliberativa, evalúan sus ventajas y méritos en comparación con otros modelos de la toma de decisión colectiva y analizan las situaciones en que 1 as deliberaciones refuerzan la calidad de la democracia.

Los autores reunidos en el volumen, no pretenden demostrar que la democracia deliberativa es siempre el recurso ideal, sino muestran también sus límites y debilidades. Mi propósito al comentar los aportes de Jon Elster y de los autores que figuran en el libro, es no sólo explicar conceptualmente los fundamentos de la democracia deliberativa, sino extraer algunos elementos teóricos que puedan derivar en necesidades educativas.

Como primer antecedente, se puede afirmar que la expresión "democracia deliberativa", ha tomado renovada vigencia en foros académicos y en publicaciones de ciencias políticas. Por ejemplo, entre las tareas fundamentales de los concejos municipales es justamente deliberar, negociar y votar todo lo que concierna al programa de gobierno del alcalde. Por lo tanto, las prácticas deliberativas serán el sustrato en la implementación del programa de trabajo del alcalde y el ejercicio de las atribuciones de esta instancia municipal. Jon Elster la analiza en los siguientes términos: "la idea de democracia deliberativa, o de toma de decisiones a través de la discusión entre ciudadanos libres e iguales, experimenta una renovación de su vigencia". (2001:13). Agrega el autor, que se debe principalmente a la influencia de Jürgen Habermas, cuando 
expresa que la idea de que la democracia gira en torno de la transformación y no en torno de la mera acumulación de ideas se haya convertido en una de las posturas principales de la teoría democrática.

Al avanzar en este marco conceptual, se puede esbozar la siguiente premisa: la toma de decisiones por parte de individuos libres, iguales y racionales no precisa adoptar la forma deliberativa. Existen otros modos de negociación -según Elster- en términos de eficiencia, equidad o aptitud intrínseca.

Con respecto a los métodos y características de la democracia deliberativa, el autor expresa que cuando un grupo de individuos iguales tiene que tomar una decisión acerca de una cuestión que les concierne a todos, y cuando la distribución inicial de opiniones no obtiene consenso, pueden sortear el obstáculo de tres maneras: discutiendo, negociando o votando. Es probable, como anota Elster, que para las sociedades modernas esta lista resulta exhaustiva. En otros tiempos se podía llegar a una decisión mediante duelos, torneos y recursos similares, pero estos hoy no se utilizan. Los grupos pueden llegar a una decisión empleando uno de los tres procedimientos, una combinación de dos de ellos, o los tres a la vez. En este sentido, tanto la discusión como la negociación constituyen formas de comunicación verbal, no así la votación. Pareciera que Elster visualiza un nuevo paradigma que permite conciliar el factor racional y el factor social que impregnan las decisiones individuales y, por ende, las elecciones colectivas.

En un proceso de toma colectiva de decisiones las preferencias de los miembros están sujetas a tres operaciones: agregación, transformación y tergiversación. La agregación de preferencias, es sinónimo de votación. Incluye el canje de votos como forma de negociación. La transformación de las preferencias a través de la deliberación racional es el objetivo manifiesto de la discusión. La tergiversación de las preferencias puede ser inducida por cada uno de los procedimientos de toma de decisiones. La votación puede ser estratégica puesto que los que negocian tienen a menudo un incentivo para presentarse a sí mismos como menos refractarios al riesgo o menos impacientes en una deliberación.

En otro nivel de análisis, Elster explica la variante que involucra los motivos de los miembros del grupo. Señala el autor que es primordial distinguir entre razón, interés y pasión. La razón es imparcial, a la vez desinteresada y desapasionada. La discusión se halla intrínsecamente relacionada con la razón, en el sentido de que quienquiera que participe en un debate debe apelar a valores imparciales. Esta instancia puede constituir una tergiversación de los verdaderos motivos, pero eso es otra cuestión. 
Tanto la negociación como la votación pueden presentarse como motivadas por cualquiera de estas actitudes.

Veamos algunos ejemplos de los tres procedimientos. La discusión pura se observa, se supone es regla general, en los jurados, en los cuales se requiere unanimidad. Incluso en este caso pueden recurrir al acuerdo tácito en virtud de su mayor habilidad para mantenerse firmes, o sea su menor impaciencia por librarse del trabajo como jurado. Como el tiempo siempre importa cuando es preciso tomar una decisión y como los que participan en el proceso habitualmente dan al futuro diferentes valores, este caso puede de hecho ser representativo.

La negociación pura es ejemplificada por aquellos juegos del tipo “divida un dólar", en los cuales los participantes efectúan ofertas y contraofertas sucesivas. El resultado se determina por el mecanismo de negociación y por el poder de negociación de las partes, o sea por los recursos que les permiten formular amenazas y promesas confiables.

La votación pura fue la concepción rousseauniana de la toma colectiva de decisiones. Los ciudadanos tenían que definir sus preferencias aislados unos de otros para evitar ser contaminados por la elocuencia y la demagogia.

La toma de decisiones políticas incluye habitualmente los tres procedimientos, por la necesidad de alcanzar una decisión lo antes posible. La votación puede surgir cuando un asunto debe decidirse en forma urgente, de modo que los participantes no disponen de tiempo para deliberar hasta alcanzarla. La negociación nace cuando los participantes valoran el tiempo de manera diferente. La negociación también surge a través del contubemio, debido a la intensidad desigual de las preferencias sobre las cuestiones que deben ser objeto de transacción y de otros mecanismos.

Después de este análisis sobre los métodos y características de la democracia deliberativa, se pueden citar algunas definiciones de los autores de capítulos del libro de Elster. En todas ellas existe un sólido núcleo de fenómenos que se consideran como democracia deliberativa. Concuerdan en que el concepto incluye la toma colectiva de decisiones con la participación de todos los que han de ser afectados por la decisión o por sus representantes; esta es la parte democrática. Concuerdan, además, en que incluye la toma de decisiones por medio de argumentos ofrecidos por y para los participantes que están comprometidos con los valores de racionalidad e imparcialidad: es precisamente la parte deliberativa.

En el capítulo del libro Democracia deliberativa, Susan Stokes (161) expresa que la deliberación mejora la calidad de las decisiones y enriquece la 
democracia”. En esta definición tanto la propaganda como el debate racional se entienden como deliberación. En el capítulo 1, Diego Gambetta, citando a Austen-Smith, define la idea por rasgos del proceso: "una conversación por la cual los individuos hablan y escuchan consecutivamente antes de tomar una decisión colectiva". De acuerdo con esta definición, la deliberación no tiene por qué tener incidencia alguna en el resultado.

Joshua Cohen (capítulo 8) y James Fearon (capítulo 2) presentan dos concepciones diferentes. Cohen va más allá del concepto de discusión para considerar la idea de "razonamiento libre y público entre iguales". Fearon, en cambio, enfatiza la idea más concreta de discusión. Su objetivo es investigar si y cuándo el fenómeno empíricamente identificable de la discusión tiene buenos resultados, en lugar de definirlo como algo intrínsecamente deseable. Es decir, que mientras Cohen trata de desarrollar las implicaciones conceptuales de la deliberación, Fearon intenta identificar las consecuencias causales de la discusión.

La deliberación o discusión pública también presenta riesgos, como los señala Benjamín Constant (p. 38). a. ser engañados a fuerza de elocuencia y estimular el conformismo, b. a través de la discusión la gente descubre las preferencias de los otros, y los más débiles pueden aceptar tímidamente a los más fuertes y c. manipulación de la información por parte de "lobbies".

En cuanto al aporte positivo de la democracia deliberativa, según Diego Gambetta, se pueden señalar cuatro aspectos importantes:

1. Lograr que los resultados de las discusiones resulten superiores a prácticas "conocidas", al permitir mejores soluciones.

2. Lograr resultados más equitativos en términos de justicia distributiva al proporcionar mejor protección a los más débiles.

3. Conducir a un consenso más amplio sobre cualquier discusión

4. Generar discusiones que sean más legítimas. (p. 41).

La deliberación democrática, como lo expresa James D. Fearon (p. 88), alude a una clase especial de discusión, que implica la seria y atenta ponderación de razones a favor y en contra de alguna propuesta, o bien a un proceso interior en virtud del cual un individuo sopesa razones a favor y en contra de determinados cursos de acción.

Como se ha señalado en líneas anteriores, la democracia deliberativa se apoya en el debate, no sólo en el sentido de que avanza mediante la discusión, sino también porque debe ser justificada mediante la argumentación. Como 
anota Elster, la deliberación es absolutamente importante, pero a la vez está lejos de resultar suficiente para garantizar la imparcialidad: ¿cómo fortalecer el sistema deliberativo que coadyuve a profundizar la democracia en las atribuciones de los concejos municipales?.

\section{H. Dimensiones teóricas de la educación no formal}

El aumento de las variables del "sistema educativo", entendido, básicamente, como sistema escolar, adquiere importancia y se está constituyendo en una de las corrientes educativas de nuestros tiempos. En esta perspectiva, se está extendiendo la convicción y lapráctica de que el "sistema educativo", en su sentido más amplio, incluyen o sólo la educación escolar, sino toda acción educativa, más o menos intencional y sistemática, que tiene lugar, tanto dentro como fuera de la institución educativa. La familia, los medios de comunicación, la iglesia, la empresa, los sindicatos, los municipios y organizaciones sociales de todo tipo, desarrollan programas y actividades de carácter educativo

Por otrolado, la prolongación de la esperanza de vida, los cambios tecnológicos, económicos y sociales exigen que el aprendizaje y la educación no se limiten al tiempo, a veces muy extenso, de la escolaridad primaria, secundaria y superior. En su lugar nos referimos a la educación como un proceso permanente vinculado al mejoramiento de las condiciones de vida de los individuos y las comunidades.

En este sentido, la educación no formal, como concepto, surge con lo consecuencia de reconocer que la educación "no puede considerarse como un proceso limitado en el tiempo y en el espacio, confinado a las escuelas y medido por los años de asistencia" (Coombs y Ahmed, 1975:26). La consecuencia de este reconocimiento ha conducido a la diferencia, dentro de la educación de tres conceptos diversos, aunque relacionados (Coombs y Ahmed, 1975:27).

Educación informal tiene aquí el sentido de un proceso que dura toda la vida y en el que las personas adquieren y acumulan conocimientos, habilidades, actitudes y modos de discernimiento mediante las experiencias diarias y su relación con el medio ambiente.

Educación formal es, naturalmente el "sistema educativo" altamente institucionalizado, cronológicamente graduado y jerárquicamente estructurado que se extiende desde los primeros años de escuela primaria hasta los últimos de la Universidad. 
Educación no formal es toda actividad organizada, sistemática, educativa, realizada fuera del marco del sistema oficial, para facilitar determinadas clases de aprendizaje a subgrupos particulares de la población, adultos como niños.

El análisis de estos tres conceptos pone en evidencia una red de relaciones de semejanza y de contraposición, de acuerdo con los criterios de duración, universalidad, institución y estructuración. Por ahora no se profundizarán estos componentes relacionales.

El trabajo de Coombs y AFMED nos recuerda cuáles fueron las preocupaciones que impulsaron el interés por la educación no formal. Sin embargo, el problema de fondo -según Sarramona, Vázquez y Colom-era uno, todavía actual: la pobreza en el ámbito rural (p.14). Ahora la pobreza de las zonas rurales se ha "urbanizado" en numerosas ciudades de América Latina.

Otro autor que se ha dedicado al estudio de la educación formal es La Belle. En su libro "Educación no formal y cambio social América Latina" señala que la introducción de la expresión "educación no formal", se acuñó para satisfacer la necesidad de respuestas extraescolares a demandas nuevas y diferentes de las que atiende ordinariamente el sistema educativo, (1980:160).

En la década de los setenta, en pleno crecimiento demográfico de los países del Tercer Mundo, (a educación no formal adquirió importancia como estrategia formativa orientada a aquellos grupos sociales que no han podido recibir una enseñanza básica completa. Así, paulatinamente, la educación no formal, fue logrando un rol significativo como orientación complementaria respecto de la educación escolar convencional. De forma parecida se expresa Hamadache cuando afirma que "la escuela ha dejado de considerarse el único lugar de enseñanza y que la enseñanza y el aprendizaje han dejado de considerarse sinónimos de "escolaridad" (1991:123). Agrega este autor, aunque muchos padres sigan asimilando enseñanza y escuela y estableciendo una relación, cada vez más hipotética, entre el "diploma" que expide la escuela y la posibilidad de obtener un empleo. Desde que Hamadache escribió esto, la inclusión de este concepto en la terminología de los sistemas educativos, la educación no formal ha logrado un significativo desarrollo y ha dado espacio a un conjunto de experiencias, actividades y acciones educativas que la sociedad venía desarrollando desde antiguo.

El avance de la educación no formal se vincula a una progresiva preocupación por el rol que debe cumplir en el fortalecimiento de una cultura política que sustente las prácticas deliberativas en los concejos municipales 
En síntesis y para concluir este trabajo, observemos el cuadro de la página siguiente que contiene cuatro conceptos básicos para la elaboración de una propuesta educativa: a. Programa de gobierno del alcalde, b. atribuciones del concejo municipal, c. Contenidos y d. prácticas deliberativas.

La interacción de los componentes que señala el cuadro puede variar según el número de miembros de los concejos y del tipo de municipalidad en que se haga el estudio de educación y democracia deliberativa. Sin embargo, tanto el programa de gobierno del alcalde como el marco de atribuciones de los concejos municipales, pueden generar un saludable clima de negociación democrática con el apoyo de una propuesta educativa elaborada sobre la base de una caracterización de contenidos didácticos expresados en prácticas deliberativas. Los pasos que siguen será diseñar un proyecto de investigación para evaluar las necesidades educativas en el ejercicio de las competencias del nuevo gobierno municipal. 


\section{Componentes que interactúan en las reuniones del concejo municipal}

\begin{tabular}{|c|c|c|c|}
\hline 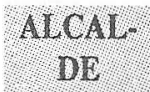 & ATRIBUCIONES DEL CONSLJO & CONTENIDOS & $\begin{array}{l}\text { PRACTICAS } \\
\text { DLLIBERATIVAS }\end{array}$ \\
\hline 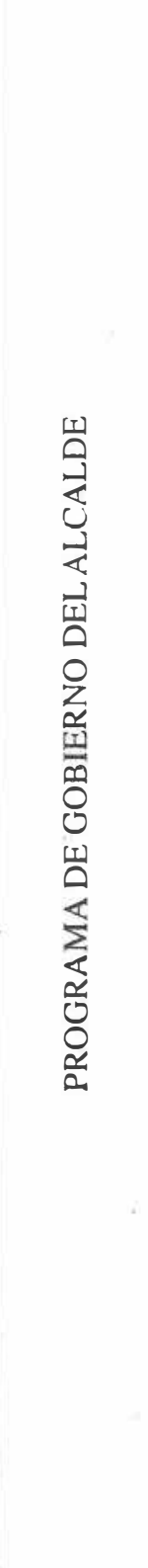 & 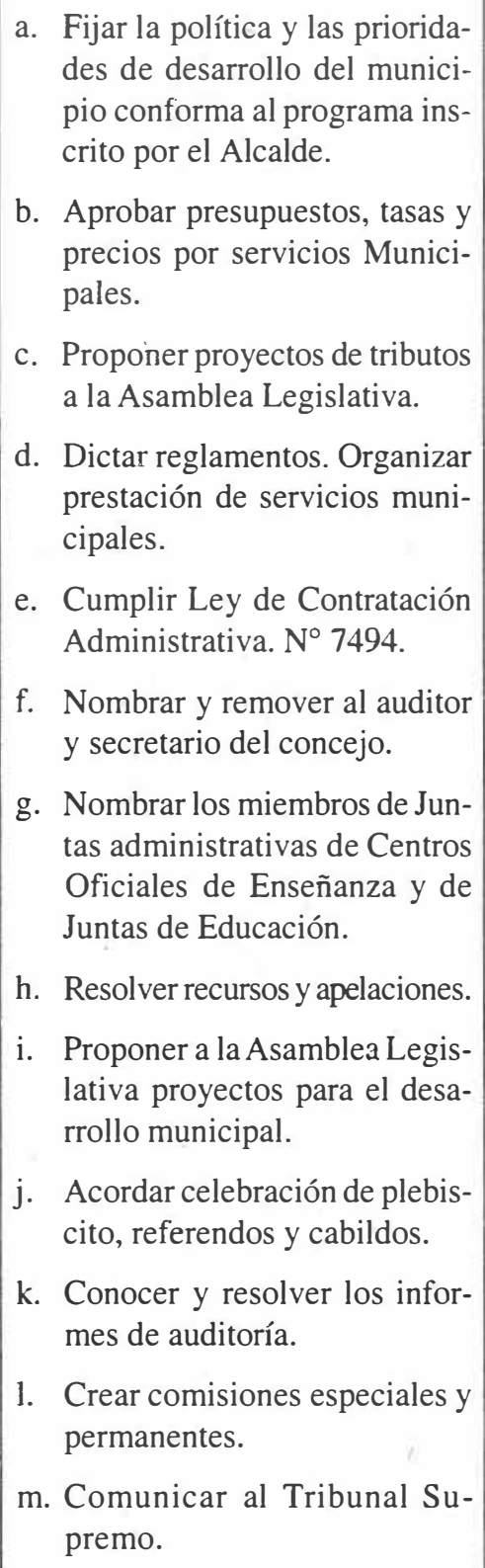 & 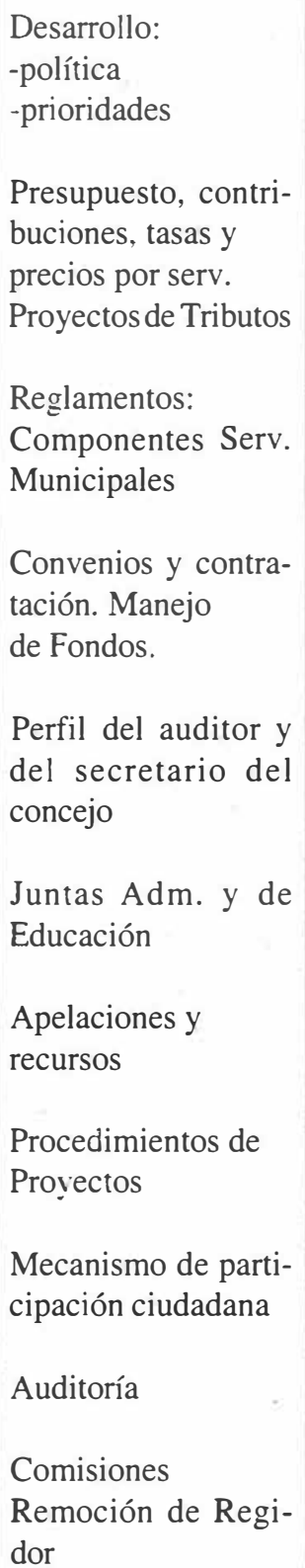 & 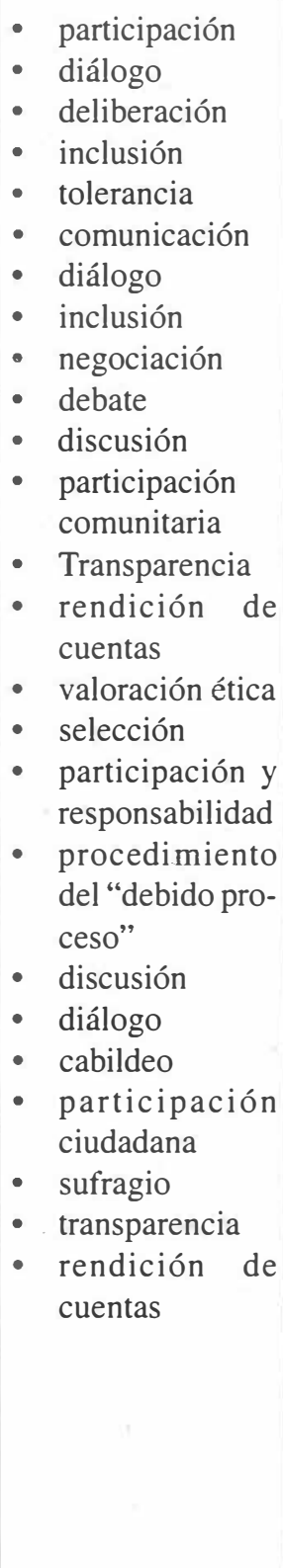 \\
\hline
\end{tabular}

Fuente: Elaboración del autor de este ensayo 


\section{REFERENCIAS}

\section{A. Libros}

Aguilar, J. y Pallavicini, V. (2002). Los desafíos de la descentralización. San José, C.R.: Instituto de Investigaciones. (IICE). Universidad de Costa Rica.

Calderón, L. (2001). Resumen Ejecutivo. En: Parlamentos, Descentralización y Desarrollo local. Washington, D.C.: Unidad para la Promoción de la democracia.

Cohen, J. (1989). Democracia y Libertad. En: La democracia deliberativa. España: Edit. Gedisa.

Coombs, P.H. y Ahmed, M. (1975). La lucha contra la pobreza rural El aporte de la educación no formal. Madrid. Tecnos.

Constant, B. (1998) Citado por Diego Gambetta en Cáp.1 ¡Claro! Ensayo sobre el machismo discursivo.

Elster, I. (2001). La democracia deliberativa. España: Editorial Gedisa.

Fearon, J. (2001). La deliberación como discusión. En: La democracia deliberativa. Elster, J.

Gambetta, D. (1998) ¡Claro! Ensayo sobre el machismo discursivo. En: Democracia deliberativa.

Hamadache, A. (1991). La educación no formal: concepto e ilustración. Perspectivas 21 (1) pp. 123-137.

House, E. y Howe, K. (2001). Valores en evaluación e investigación social. España: Ediciones Morata.

La Belle, T.J. (1980). La educación no formal y cambio social en América Latina. México: Nueva Imagen.

Przeworski, A. (2001). Deliberación o dominación ideológica. En: La democracia deliberativa. Elster, J.

Rivera, R. (2001). Cultura Política, Gobierno Central y Descentralización. El Salvador: FLACSO Programa El Salvador.

Sarramona, J., Vázquez, G., y Colom, A. (1998). Educación no formal. Barcelona: Editorial Ariel, S.A.

Sartóri, G. (2001). Teoría de la democracia. El debate contemporáneo. Madrid: Alianza Universitaria.

Stokes, S. (1998) Patologías de la deliberación. En: Democracia deliberativa.

Touraine, A. (1994). ¿Qué es la democracia? España: Temas de Hoy. Ensayo.

\section{B. Revistas}

Carazo, M. (1996). Ciudadano, parlamento y medios de comunicación. Revista Parlamentaria. Asamblea Legislativa. Pp. 17-34. 
Castro, J. (1999). El retorno del ciudadano: los inestables territorios de la ciudadanía en América Latina. Perfiles Latinoamericanos. FLACSO N ${ }^{14}$. Pp. 39-62.

Chaves, E. (1998). La elección popular del alcalde municipal: un mecanismo de democracia participativa en el ámbito local. En: Revista Parlamentaria. Vol. 6. $N^{\circ} 2$. Agosto 1998. Asamblea Legislativa de Costa Rica.

Patrick, J. (1997). Principios de la democracia para la educación de los ciudadanos. Rev. Latinoamericana de Estudios Educativos. (México). Vol. XXVII). núms. 1 y 2 . Pp. 165-201.

\section{Documentos}

Código Municipal y Legislación Conexa. (2001), versión actualizada por Rubén Solano. San José, C.R.: Edit. Editores S.

Descentralización, responsabilidad y participación: consecuencias políticas de la reforma municipal en Costa Rica. Jeff Ryan (University of Arkansas), y Justo Aguilar F. (Universidad de Costa Rica) (documento de estudio, sin fecha).

Expediente $\mathrm{N}^{\circ}$ 14.310. Dictamen Unánime Afirmativo. Transferencia de Competencias y Fortalecimiento de los Gobiernos Locales. Comisión Especial de Reforma Política y del Régimen Municipal (17 de octubre de 2001).

Encuesta de Opinión. (2001). Instituto de Estudios Sociales y Población (IDESPO). Heredia, C.R.: Universidad Nacional.

Estudio de Opinión. (2001). Unidad de Investigación y Mercadeo (UNIMER).

\section{Periódicos}

Mora, G. Actitudes del Alcalde. La Nación, 27 de octubre del 2002 (P. 5A.)

Sojo, C. La hora de lo local. Para beneficio de la comunidad cantonal. La Nación, 25 de setiembre de 2002.

. Diálogo nacional. La Nación, 5 de junio de 2003.

Vargas, J. Capacidad de negociación entre alcalde y munícipes. La Nación, 27 de octubre de 2002 (P. 5A). 